\title{
CLINICAL PROFILE AND DIAGNOSIS OF TAKAYASU ARTERITIS- STUDY FROM A TERTIARY CARE HOSPITAL
}

\author{
Kamalakar Kosarajuㄴ, Suneetha $K^{2}$, Subba Reddy Venkata Yerrabandi'3 , Adikesava Naidu Otikunta ${ }^{4}$
}

${ }^{1}$ Assistant Professor, Department of Cardiology, NRI General Hospital, Guntur, Andhra Pradesh, India.

${ }^{2}$ Associate Professor, Department of Cardiology, Gandhi Medical College, Hyderabad, Telangana, India.

3 Professor and HOD, Department of Cardiology, Osmania General Hospital, Hyderabad, Telangana, India.

${ }^{4}$ Professor, Department of Cardiology, Osmania General Hospital, Hyderabad, Telangana, India.

\section{BACKGROUND}

ABSTRACT

Takayasu arteritis (TA) is a rare, chronic, idiopathic, large vessel panarteritis majorly affecting young females in second or third decade of their life. The disease is not biased to any particular ethnicity and prevalence varies as per geological whereabouts. The aim of the present study to determine the clinical profile and diagnosis of patients of Takayasu's arteritis presenting to the hospital.

\section{MATERIALS AND METHODS}

The descriptive study was a single centre, prospective, observational study conducted between October 2012 and March 2015 at a hospital located in India. A total of 25 patients were included in this study. Basic demographic details like age, gender, family history, socioeconomic status, presenting complaints and other vital data of all patients were recorded. After that, all the patients underwent systemic examination which included auscultation, complete blood picture, renal function test, C reactive protein levels, chest X-ray, computed tomography or magnetic resonance angiography, coronary angiography, peripheral angiography, aortogram, 4-vessel angiography.

\section{RESULTS}

Out of the total 25 patients, $36 \%(n=9)$ belonged to $21-30$ years and 31-40 years age group with the mean age being $26.52 \pm 9.28$ years. Female vs male ratio was 20:5 (4:1) with a female preponderance. Majority of patients (40\%) were suffering from type-V TA followed by type-I (20\%) and type-II b (20\%) in the present study.

\section{CONCLUSION}

About three fourth (72\%) belonged to 21-40 years age group with female preponderance. Hypertension was the most common presentation. Majority had discrepancy of pulses. About one third (32\%) had left ventricular systolic dysfunction. Majority of patients (40\%) were suffering from type-V TA.

\section{KEY WORDS}

Takayasu Arteritis; Prospective; Clinical Presentation; Diagnosis.

HOW TO CITE THIS ARTICLE: Kosaraju K, Suneetha K, Yerrabandi SRV, et al. Clinical profile and diagnosis of Takayasu arteritisstudy from a tertiary care hospital. J. Evolution Med. Dent. Sci. 2019;8(01):58-61, DOI: 10.14260/jemds/2019/13

\section{BACKGROUND}

Takayasu's arteritis (TA), also known as pulseless disease, occlusive thromboaortopathy, and Martorell syndrome,[1] is a chronic inflammatory arteritis affecting large vessels, predominantly the aorta and its main branches. Vessel inflammation leads to wall thickening, fibrosis, stenosis, and thrombus formation. Symptoms reflect end organ ischaemia. More acute inflammation can destroy the arterial media and lead to aneurysm formation.[2] Early reports suggested that the disease was confined to females from Eastern Asia, but it has now been recognised worldwide in both sexes, although disease manifestations vary between populations. The female to male ratio appears to decline from Eastern Asia towards the West.

'Financial or Other Competing Interest': None.

Submission 28-11-2018, Peer Review 22-12-2018,

Acceptance 29-12-2018, Published 07-01-2019.

Corresponding Author:

Dr. Suneetha K,

Associate Professor,

Department of Cardiology,

Gandhi Medical College,

Hyderabad-500003, Telangana, India.

E-mail: drsuneethaleo@gmail.com

DOI: $10.14260 /$ jemds $/ 2019 / 13$
Diagnosis of TA is quite difficult in its early phase as there is no standard test that can accurately diagnose the disease. The early phase of TA is overshadowed by numerous nonspecific symptoms, these involve headache, fever, malaise, night sweats, rashes, anorexia, weight loss, and arthralgia and in some patients marked elevation of erythrocyte sedimentation rate (ESR) was also observed. TA can be suspected from physical examination, laboratory and imaging findings. Several authors have proposed various diagnostic models to detect TA.[3-5] Of these, the criteria provided by American College of Rheumatology (ACR) ${ }^{[5]}$ have $90.5 \%$ sensitivity and $97.8 \%$ specificity. Based on ACR criteria of TA, this study aims to determine the clinical profile and diagnosis of patients of Takayasu's arteritis presenting to the hospital.

\section{MATERIALS \& METHODS}

Study Design and Patient Population

The descriptive study was a single centre, prospective, observational study conducted between October 2012 and March 2015 at a hospital located in India. A total of 25 patients were included in this study. Basic demographic details like age, gender, family history, socioeconomic status, presenting complains and other vital data of all patients were recorded. After that, all the patients underwent systemic 
examination which included auscultation, complete blood picture, renal function test, $\mathrm{C}$ reactive protein levels, chest $\mathrm{X}$ ray, computed tomography or magnetic resonance angiography, coronary angiography, peripheral angiography, aortogram, 4-vessel angiography.

\section{Inclusion/Exclusion Criteria}

Patient was considered to be suffering from TA if at least 3 of the following 6 criteria were fulfilled as per revised ACR 1990 criteria,[5] for classification of TA-

1. Age $\leq 40$ years at onset of disease,

2. Claudication of the extremities,

3. Decreased pulse in branchial artery,

4. Difference in systolic blood pressure $>10 \mathrm{mmHg}$ between the arms,

5. Angiographic evidence of narrowing or occlusion of entire aorta, and

6. Bruit over the subclavian arteries or aorta.

Angiographic classification criteria were used to define types of TA,[6] where-

\begin{tabular}{|c|c|}
\hline Type & Vessel Involvement \\
\hline Type I & Branches from the aortic arch \\
\hline Type II a & Ascending aorta, aortic arch and its branches \\
\hline Type II b & $\begin{array}{c}\text { Ascending aorta, aortic arch and its branches, } \\
\text { thoracic descending aorta }\end{array}$ \\
\hline Type III & $\begin{array}{c}\text { Thoracic descending aorta, abdominal aorta, } \\
\text { and/or renal arteries }\end{array}$ \\
\hline Type IV & Abdominal aorta and/or renal arteries \\
\hline Type V & Combined features of types IIb and IV \\
\hline
\end{tabular}

New angiographic classification of Takayasu arteritis, Takayasu conference 1994.

Informed consent was taken from the study participants before start of the study and confidentiality was ensured.

\section{Statistical Analysis}

Data was entered in Microsoft Excel 2010 version and analysis using EPI INO version 7 provided by CDC Atlanta. Continuous variables are presented as mean \pm standard deviation (SD) and categorical variables as counts and percentages.

\section{RESULTS}

Out of the total 25 patients that were included in the study, $36 \%(n=9)$ belonged to 21-30 years and 31-40 years age group each with the mean age being $26.52 \pm 9.28$ years.

\section{Sex}

Female vs male ratio was 20: 5 (4:1) with a female preponderance. Males were comparatively elder than females with mean age being $29.20 \pm 7.75$ in Males and 25.85 \pm 9.50 in Females but this not significant statistically $(\mathrm{p}=0.4)$.

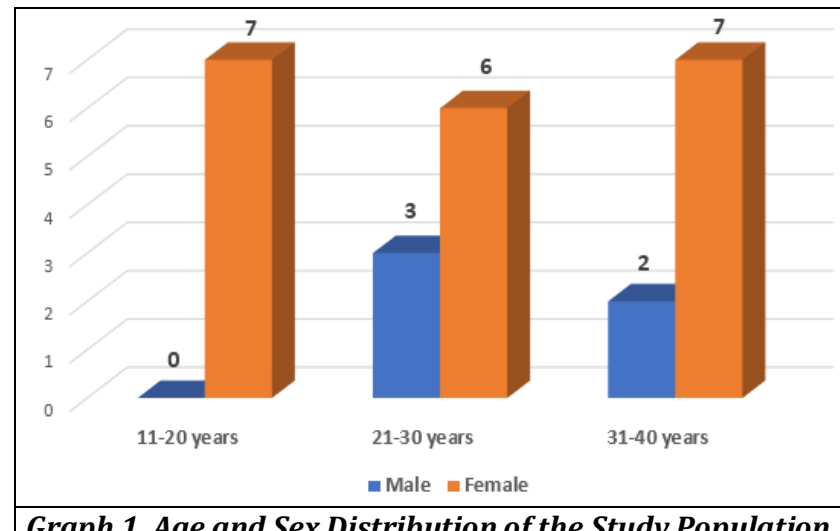

Graph 1. Age and Sex Distribution of the Study Population
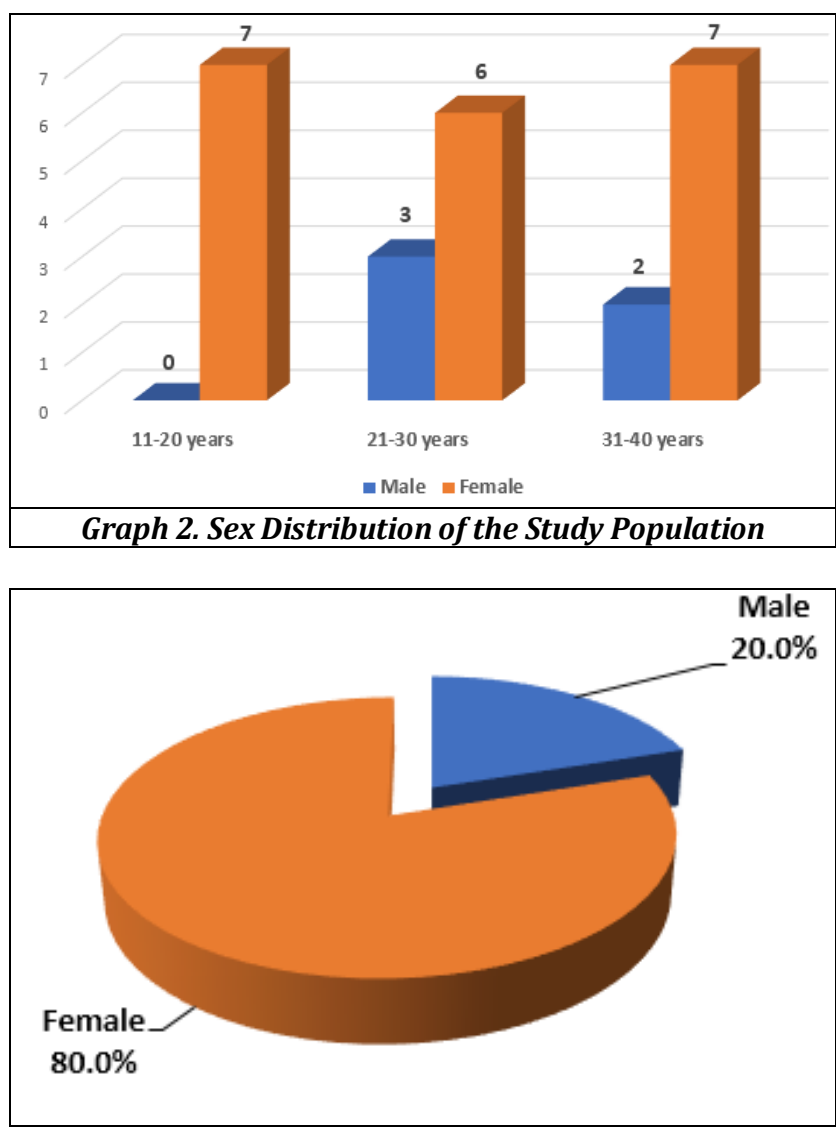

\section{Presentation}

With regards to clinical presentation, Hypertension (BP > $140 / 90 \mathrm{mmHg}$ was the most common presentation (20 cases $(80 \%)), 1$ patient presented with malignant hypertension with seizures (4\%) and 1 patient had stroke as the initial presentation. (4\%). Hypertension was considered when is Systolic blood pressure more than 140 and diastolic more than $90 \mathrm{~mm} \mathrm{Hg}$.

Left ventricular systolic dysfunction (ejection fraction < $50 \%$ ) was present in 8 cases (32\%). Out of these 7 (28\%) patients had moderate left ventricular systolic dysfunction (30-40\%) and one patient (4\%) had mild left ventricular systolic dysfunction (40-50\%). 
- $\quad$ Discrepancy of pulses was present in 21(84\%) patients.

- Discrepancy of pulses of upper limb were present in 15 (66.7\%) patients.

- $\quad$ Diminished lower limb pulses were present in $9(36 \%)$ patients.

Total three cases had Aortic regurgitation (AR), of whom two had severe AR and one mild AR. One male patient with mild Aortic Regurgitation also had mild Tricuspid Regurgitation. One patient was referred for aortic valve replacement.

All the patients except one patient had recovery from hypertension and heart failure during the course of the disease. Hypertension was on reasonable control with drugs and interventional management.

1 patient was found to have coexisting pulmonary tuberculosis and recovered with Anti-tuberculous therapy. One patient was found to have CNS vasculitis and responded to anti-tuberculous treatment.

\begin{tabular}{|c|c|c|}
\hline Clinical Manifestations & Number & Percentage \\
\hline Hypertension & 20 & $80 \%$ \\
\hline Discrepancy of pulses & 21 & $84 \%$ \\
\hline Diminished pulses & 09 & $36 \%$ \\
\hline Left ventricular systolic dysfunction & 08 & $32 \%$ \\
\hline Seizures & 01 & $4 \%$ \\
\hline Stroke & 01 & $4 \%$ \\
\hline Table 1. Clinical Manifestations in Takayasu Arteritis
\end{tabular}

\section{ESR Findings}

Inflammatory markers such as erythrocyte sedimentation rate (ESR) are commonly used to monitor disease progression in Takayasu arteritis due to their affordable nature and non-invasive nature.

In the present study, the mean ESR among the patients was $43.04 \pm 27.45 \mathrm{~mm} /$ hour.

ESR of more than $20 \mathrm{~mm} /$ hour was present in 19 (76\%) patients at presentation.

\section{Serum Creatinine}

Out of the 25 patients, 8 patients had higher serum creatinine values above 2.0 at presentation which recovered. Only then they were taken for angiography or intervention.

\begin{tabular}{|c|c|c|}
\hline ESR Group (mm/hour) & Number & Percentage \\
\hline Up to 20 & 06 & $24 \%$ \\
\hline $20-40$ & 08 & $32 \%$ \\
\hline $40-60$ & 06 & $24 \%$ \\
\hline $60-80$ & 03 & $12 \%$ \\
\hline 80 \& above & 02 & $8 \%$ \\
\hline \multicolumn{2}{|c|}{ Table 2. ESR Findings in the Present Study } \\
\hline
\end{tabular}

With regards to arterial involvement, carotid artery, subclavian artery and renal artery were more commonly affected with $40 \%, 60 \%$ and $48 \%$ respectively.

Vertebral artery was affected in $10 \%$ of the cases. Other arteries affected were coeliac axis, Right bronchio-cephalic artery, Right anterior cerebral artery, Superior mesenteric artery, right common iliac artery and femoral artery.

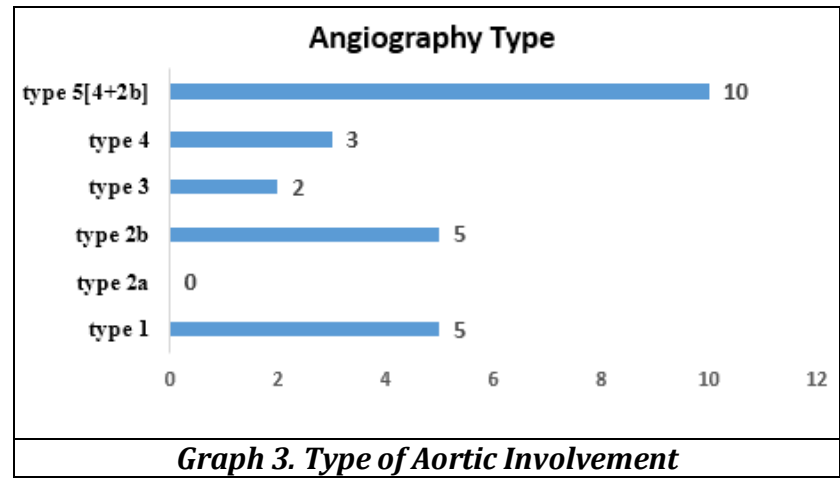

According to the new angiographic classification of TA, majority of patients $(40 \%)$ were suffering from type-V TA followed by type-I (20\%) and type-IIb (20\%) in the present study.

\section{DISCUSSION}

Takayasu's arteritis (TA) is a chronic vasculitis involving mainly the aorta and its branches, as well as the pulmonary and coronary arteries. The classical definition of Takayasu's Arteritis is that of chronic, progressive, inflammatory, occlusive disease of the aorta and its branches. Takayasu arteritis has a global distribution but observed more frequently in Asia than other continents. TA is the most common cause of renovascular hypertension in many south east Asian countries including India.[7]

With regards to demographic characteristics, the present study found that about three fourth (72\%) were from 21-40 years age group with female preponderance.

In concurrence to study findings, study by SK Sharma et al[8] found that the mean age of the patients at presentation was 24.7 years. The youngest and oldest patients were aged 6 years and 45 years respectively. The male to female ratio was 1:1.2.

The most common presentation was hypertension in the present study which was similar to findings by Muranjan MN et al (2000)[9] where the commonest presenting features were hypertension (64.7\%), congestive cardiac failure (47\%), weak or absent peripheral pulses, cardiomyopathy (41.1\% each) and cardiac valvular affection (35.2\%). Retinopathy, hypertensive encephalopathy and abdominal bruits were uncommon. None presented in the prepulseless phase. Another study on clinical and therapeutic aspects by Marila Duarte Brandao Panico et al (2007)[10] from Brazil found that Hypertension was present in more than three fourth $(85.2 \%)$, and upper and lower limb claudication in $69.5 \%$ and $30.5 \%$, respectively. ESR was $>60 \mathrm{~mm} /$ hour in half the cases. Autoimmune diseases, Tuberculosis and HIV correlated in $19.4,8.3$ and $2.7 \%$, respectively.

Raised ESR was present in $76 \%$ of the cases in the present study which was similar to findings by Ye Feng et al (2017) [11] from China where raised ESR was seen in $90 \%$ cases.

In study by SK Sharma et al[8] observed that two patients each had upper limb and lower limb claudication and one patient had abdominal angina. Visual blurring was reported by two patients. Jaw claudication was not reported by any patient. Hypertensive retinopathy was seen in twenty patients but Takayasu's retinopathy was not seen in any case. ESR more than $20 \mathrm{~mm}$ in first hour was seen in 16 patients (54\%). Only three patients out of seven with systemic features had raised ESR. 
A study on circulation levels of acute phase proteins with Takayasu arteritis by Juan Ma (2010) ${ }^{[12]}$ from China reported that ESR was more frequently elevated in active-phase patients $(83.3 \%)$ than in inactive-phase patients $(28 \%)$. The mean ESR was $39.1 \pm 24.8 \mathrm{~mm} / \mathrm{h}$ in active TA compared with $15.2 \pm 9.6 \mathrm{~mm} / \mathrm{h}$ in inactive $\mathrm{TA}(\mathrm{P}<.001)$ and $11.3 \pm 5.1$ $\mathrm{mm} / \mathrm{h}$ in controls $(\mathrm{P}<.001)$.

Majority of patients (40\%) were suffering from type-V TA followed by type-I (20\%) and type-IIb (20\%) in the present study. Similarly, a Mexican study[13] showed that $69 \%$ patients suffered from type-V followed by $19 \%$ with type-I, whilst a study conducted in China[14] reported showed more patients suffered from type-I (29.3\%) followed by type-V (25.8\%) TA.

The combined involvement was the most common type which is the case with Japanese, Indian, as well as European studies. Involvement of aortic arch branches alone (Type 1) was see in $6(25 \%)$ patients. This was higher than observed in the studies from Indian patients such as Subramanyam et al.[15]

In contrast, Muranjan MN et al (2000) ${ }^{[9]}$ found that the predominant pattern of angiographic affection was Type II (52.9\%). This difference in the study findings might be attributed to the difference in the age groups that were taken in the studies.

\section{CONCLUSION}

A total of 25 patients were included in the present study in the study duration of October 2012 and March 2015 at a tertiary care hospital. About three fourth $(72 \%)$ belonged to 21-40 years age group with female preponderance. Hypertension was the most common presentation. Majority had discrepancy of pulses. About one third (32\%) had left ventricular systolic dysfunction. In three fourth cases, ESR was more than $20 \mathrm{~mm} /$ hour. With regards to arterial involvement, carotid artery, subclavian artery and renal artery were more commonly affected with $40 \%, 60 \%$ and $48 \%$ respectively. Majority of patients (40\%) were suffering from type-V TA.

\section{REFERENCES}

[1] Lupi-Herrera E, Sánchez-Torres G, Marcushamer J, et al. Takayasu arteritis. Clinical study of 107 cases. Am Heart J 1977; 93(1):94-103.

[2] Numano F, Okawara M, Inomata H, et al. Takayasu's arteritis. Lancet 2000;356(9234):1023-5.
[3] Fiessinger J, Tawfik-Taher S, Capron L, et al. Takayasu's disease. Diagnostic criteria (author's transl). La Nouvelle Presse Medicale 1982;11(8):5836.

[4] Ishikawa K. Diagnostic approach and proposed criteria for the clinical diagnosis of Takayasu's arteriopathy. J Am Coll Cardiol 1988;12(4):964-72.

[5] Arend WP, Michel BA, Bloch DA, et al. The American College of Rheumatology 1990 criteria for the classification of Takayasu arteritis. Arthritis Rheum 1990;33(8):1129-34.

[6] Hata A, Noda M, Moriwaki R, et al. Angiographic findings of Takayasu arteritis: new classification. Int J Cardiol 1996;54 Suppl:S155-63.

[7] Editorial. Takayasu's arteritis: an Indian perspective. Eur J Vasc Endovasc Surg 2007;33:578-82.

[8] Sharma SK, Sangameswaran KV, Kalra SP. Clinical profile of Takayasu's arteritis Med J Armed Forces India 1998;52(2):140-2.

[9] Muranjan MN, Bavdekar SB, More V, et al. Study of Takayasu's arteritis in children: clinical profile and management. J Postgrad Med 2000;46(1):3-8.

[10] Panico MDB, Spichler ES, Rodrigues LCD, et al. Takayasu's arteritis: clinical and therapeutic aspects in 36 patients. J Vasc Bras 2007;7(2)123-30.

[11] Feng Y, Tang X, Liu M, et al. Clinical study of children with Takayasu arteritis: a retrospective study from a single center in China. Pediatr Rheumatol Online J 2017;15(1):29.

[12] Ma J, Luo X, Wu Q, et al. Circulation levels of acute phase proteins in patients with Takayasu arteritis. Journal of Vascular Surgery 2010;51(3):700-6.

[13] Soto ME, Espinola N, Flores-Suarez LF, et al. Takayasu arteritis: clinical features in 110 Mexican Mestizo patients and cardiovascular impact on survival and prognosis. Clin Exp Rheumatol 2008;26(3 Suppl 49):S9-15.

[14] Yang Y, Tian T, Yang K, et al. Outcomes of percutaneous coronary intervention and coronary artery bypass grafting in patients with Takayasu arteritis. Int J Cardiol 2017;241:64-9.

[15] Subramanyan R, Joy J, Balakrishnan KG. Natural history of aortoarteritis (Takayasu's disease). Circulation 1989;80(3):429-37. 